\title{
Proposta de alteração de layout para melhoria no fluxo de produção de uma Indústria Automotiva
}

\section{Carline Kühl Gennaro}

Caroline_kuhl@yahoo.com.br

Universidade Metodista de Piracicaba (UNIMEP), Santa Bárbara D’Oeste, SP, Brasi

Everton Dias de Oliveira Everton_deoliveira20@hotmail.com Universidade Metodista de Piracicaba (UNIMEP), Santa Bárbara D'Oeste, SP, Brasil

Fábio Franco de Oliveira Fabio.oliver1@outlook.com Faculdades Integradas Einstein de Limeira (FIEL), Limeira, SP, Brasil

Danilo de Freitas Silva Danilofreitas 07@hotmail.com Faculdades Integradas Einstein de Limeira (FIEL), Limeira, SP, Brasil

\author{
RESUMO
}

O problema de pesquisa deste trabalho se delimita na verificação de melhoria possível em um arranjo físico de uma determinada na linha de produção. Tendo como objetivo de, apresentar alternativas para solucionar as deficiências encontradas nas alterações de layout da fabril a partir de um estudo de caso, aplicando uma mudança de layout de acordo com o estudo do tempo do equipamentos, da movimentação dos operadores e também do tempo de fluxo do produto, levando em consideração todo o espaço físico atual.A metodologia empregada neste estudo prático, se estruturou em buscar na literatura científica focada na Engenharia de Produção, os conceitos de OEE (Overall Equipment Effectiveness) e TPM (Total Productive Maintenance) e Lean Manufacturing, aplicando em um estudo de caso prático.Como resultado, a alteração de layout proporcionou a cada operador desta linha de produção ganhos de no mínimo 6 segundos em suas operações, reduzindo o tempo total de ciclo desta linha em aproximadamente $3 \%$, já que esse novo layout facilitou a entrada e saída do produto e permitiu que o produto seja retirado por empilhadeira, reduzindo assim os esforços dos operadores e otimizando a circulação interna.
\end{abstract}

PALAVRAS-CHAVE: Layout. Industria automotiva. Arranjo Físico. 


\section{INTRODUÇÃO}

O êxodo rural, seguido do crescimento populacional aumentou-se a gama de necessidades da população de modo geral, assim como os hábitos foram se modificando e a tecnologia foi sendo utilizada em aprimoramento das atividades produtivas (NEVES et al, 2018). O surgimento de máquinas com capacidade produtiva de lote de peças por minuto, requerem maior ergonomia e otimização dos espaços físicos no interior fabril (KIRAN, 2017).

A cadeia produtiva cresceu exponencialmente principalmente nos anos 80 , onde as linhas de produção automatizadas ganharam força principalmente no setor automobilístico. As vendas na internet a partir de meados dos anos 90 , foi outro fator impactante e fonte de prosperidade para todos os setores produtivos, amadurecendo ainda mais a globalização dos processos produtos (ALLAIS et al, 2015).

Muitas indústrias possuem plantas de trabalhos em lugares distintos e algumas delas em alguns casos em países diferentes, mas seus processos organizados de maneira enxuta fazem com que estas distâncias sejam vantajosas do ponto de vista financeiro, pois cada região ou nação possui uma fonte de tributação distinta da outra o que contribui para a descentralização das plantas produtivas (HALLSTEDT et al, 2013). Prova disso são automóveis e aparelhos eletrônicos onde, por exemplo: têm parte de seus processos ou peças e até mesmo o produto por inteiro, manufaturados na China por ser um país caracterizado em ter maior carga horária de trabalho semanal, salários dos funcionários reduzidos, contribuindo assim para um valor menor na unidade do produto final, e posteriormente são distribuídos por todo o mundo (FERRÀS-HERNÁNDEZ et al, 2017).

A eficiência de um sistema produtivo se deve a diversos fatores conhecidos como: pré-projeto, planejamento, execução do projeto e processo produtivo, planejamento da produção do produto, adequação de sistemas, ferramentas, a capacidade técnica de cada colaborador perante a sua função de exercício, e também a própria estratégia de gestão do projeto. Porém outro ponto determinante e não muito citado é o layout de trabalho de cada posto de atividade e linha de produção, juntos eles tem uma porcentagem representativa dentro da eficiência da produção como um todo (FAN et al, 2018).

Com um layout adequado as empresas puderam avaliar melhor o rendimento de suas operações e colaboradores, fazendo com que em alguns casos os processos pudessem ser otimizados, e alguns pontos durante as etapas produtivas fossem otimizados. Resultando em menores tempos de trabalho para produção do produto final (RAHMAN et al, 2014).

Apesar disso com a crise econômica, as empresas passaram a pensar no layout como um fator essencial para readequação de seus processos, contribuindo para contenção de espaços e gastos dentro da planta de manufatura (FAHAD et al, 2017).

Com a economia em constante desaceleração afetando vários segmentos o mercado automobilístico foi o mais atingido, fato parecido a este que não ocorria em 20 anos no país, essa situação surpreendeu todas as indústrias, principalmente do setor automotivo, fazendo com que os números de vendas despencassem com relação a 2009, ano em que o setor automobilístico registrou o maior número de vendas de unidades da história (SUJOVA, 2015). Isso motivou as indústrias a 
tomarem novas medidas para se manterem competitivas, ou no mínimo possível para se adaptarem as mudanças impostas pelo mercado.

Observou-se que as indústrias começaram a reajustar o seu espaço físico para melhorar a eficiência que fora prejudicada pelo acúmulo de máquinas e equipamentos ociosos, decorridos da falta de demanda. No estudo de caso deste trabalho constatou-se uma obstrução do fluxo na linha de produção, ocasionado por essas mudanças de layout, os principais problemas decorridos foram: parada de linha, movimentação excessiva dos operadores em decorrência disso uma queda dos indicadores da produtividade. Um layout mal organizado é responsável pela baixa produtividade e uma qualidade ruim, isso faz com que haja a necessidade de uma readequação para minimizar os desperdícios (ZERELLA et al, 2017).

Desta maneira, este artigo apresenta o seguinte problema: o que é possível de ser realizado para melhorar o arranjo físico na linha de produção? Sendo, o objetivo geral deste trabalho, analisar e propor melhoria no arranjo físico desta linha, de maneira que reduza a movimentação dos operadores e melhore os indicadores de produtividade da organização.

Para a solução do problema em questão acredita-se que a readequação do arranjo físico pode suprir essas necessidades, tornando a célula de montagem eficiente e alavancando os indicadores de resultados da empresa. Outra alternativa pode ser a implantação de políticas de melhorias como o Lean Manufacturing e Six Sigma a fim de reduzir custos decorrentes de movimentação e espera (MARZAGÃO e CARVALHO, 2016).

A alteração e aplicação de um novo layout sugerido neste trabalho tende a contribuir para as demais empresas do setor que tenham este mesmo problema. Podendo assim estarem preparados para reconhecer as falhas, aplicando alterações que venham beneficiar o fluxo do produto, pode ser um fator determinante para a permanência e aceitação das novas condições do mercado com menos disponibilidade de recursos a serem empregados na infraestrutura da planta fabril. Este estudo de caso apresentará métodos e ferramentas necessárias em um processo de alteração de layout e auxiliará na tomada de decisão dos gestores (D'ANTONIO et al, 2018).

\section{OBJETIVO}

O objetivo deste trabalho é apresentar alternativas para solucionar as deficiências encontradas nas alterações de layout da fábrica a partir de um estudo de caso, aplicando uma mudança de layout de acordo com o estudo do tempo do equipamentos, da movimentação dos operadores e também do tempo de fluxo do produto, levando em consideração todo o espaço físico atual. Uma vez que definindo essas ferramentas é possível diminuir o movimento de pessoas e materiais, melhorando a qualidade do trabalho, sem a necessidade de realizar muitos investimentos, tudo isto permitirá melhorias nas condições de trabalho (SLACK et al, 2008). 


\section{REFERENCIAL BIBLIOGRÁFICO}

Esta seção contempla o referencial bibliográfico deste trabalho, abrangendo os seguintes tópicos: layout, adequação de layout e OEE (Overall Equipment Effectiveness).

Tendo como objetivo encontrar na literatura conceitos de layout e seus tipos, e encontrar qual a melhor maneira de se administrar os possíveis problemas com a sua implantação. Outro enfoque dessa revisão será a de verificar quais são as ferramentas do Lean Manufacturing e como utilizá-las para medir os resultados de produtividade.

\section{LAYOUT}

O layout de uma empresa é um sistema de referência física e visual, onde são agrupados os equipamentos, os recursos e a mão de obra, tendo a capacidade de harmonizar e obter melhores rendimentos das operações, deixando assim o espaço físico mais eficaz. De acordo com Jones e George (2008) o layout tem o objetivo de criar a interface homem-máquina para aumentar a eficiência do sistema de produção.

O arranjo físico possui características de uma operação produtiva e acaba se tornando a parte mais aparente de qualquer organização, mostrando o quão seu aspecto e sua forma são muito importantes, para o desempenho fabril (ESMAEEL et al, 2018).

Pensar de maneira condensada sobre as atividades que se pretende desempenhar em terminado espaço, capacidade produtiva que se pretende atingir, variedade de itens a serem produzidos, também são caminhos que contribuem para um bom planejamento e projeto de execução de layout (NEUMANN e FOGLIATTO, 2013).

Durante a fase de planejamento e dimensionamento em de uma determinada indústria ou empresa, seja ela de qual for sua atividade, engenheiros e arquitetos discutem as atividades a serem desenvolvidas em tal planta como estratégia inicial para alocação de equipamentos, operadores, estações de trabalho, linhas de montagem, área de logística e estoque. Pois a eficiência do movimento de execução do trabalho final quando associada com o layout tende a ser positiva, uma vez que todos os recursos estão devidamente adequados com cada função de trabalho e operação (NEUMANN e FOGLIATTO, 2013).

Rosa et al (2014), em um estudo realizado sobre a reorganização do layout como estratégia de otimização, onde a partir de um estudo exploratório com base em um estudo de caso em uma indústria do setor produtivo de cilindros hidráulicos na Serra Gaúcha na região Sul do Brasil, uma série de entrevistas foram realizadas de maneira estruturada com os membros pertencentes à corporação. $O$ estudo então apresentou linhas de aprimoramento no ambiente de trabalho, revertendo em lucros definitivos para a empresa, com a adequação do layout se revertendo até em antecipação do capital de investimento aplicado na empresa.

Já Fernandes et al (2016), no seu trabalho sobre: layout de empresas e seus benefícios, em questão foi analisada uma empresa com seu processo de produção considerado crítico pois não se trada de uma empresa com fabricação de produtos em série, cada produto produzido não possui semelhança com o outro, isso se deve 
as exigências feitas por cada cliente. As análises permitiram mostrar que uma alteração de layout era necessária para atender uma linha de produção com produtos diferentes sendo ali fabricados, os resultados pós mudança de layout foram satisfatórios podendo ser aplicados às demais empresas do segmento e perfil de produção.

\section{ADEQUAÇÃO DO LAYOUT}

Para a adequação de um novo layout é necessário que se faça um estudo para compreender o espaço a ser transformado, buscando alternativas para deixar a planta de fabricação eficiente. Essa mudança não se restringe somente às indústrias automotivas, mas passam também por exemplo em lojas, empresas contábeis, fabricantes de turbinas hidrelétricas, escritórios, centros de distribuição e até mesmo em restaurantes. Pequenas alterações nos layouts podem gerar enormes ganhos em produtividade, porém cabe aos administradores saber a melhor forma de aplicar (AZEVEDO, 2017).

Por existir uma variedade de processos distintos e necessidades diferentes para a produção de diversos tipos de produtos, podemos citar alguns tipos de layout e suas principais características na Tabela 1:

Tabela 1 - Apresentação das características de cada layout

\begin{tabular}{|c|c|}
\hline Tipo & Descrição \\
\hline $\begin{array}{l}\text { Layout Celular } \\
\text { ou Tecnologia } \\
\text { de Grupo }\end{array}$ & $\begin{array}{l}\text { Flexibilidade quanto ao tamanho de lote por produto; Específico para } \\
\text { uma Família de Produtos; Diminui o transporte do material; Diminui } \\
\text { os estoques; Centraliza a responsabilidade sobre o produto fabricado; } \\
\text { Permite elevado nível de qualidade e de produtividade; }\end{array}$ \\
\hline Layout Por & Para produção com pouca ou nenhuma diversificação, em quantidade \\
\hline $\begin{array}{l}\text { Produto ou em } \\
\quad \text { Linha }\end{array}$ & $\begin{array}{l}\text { constante ao longo do tempo e em grande quantidade; Alto } \\
\text { investimento em máquinas; Pode apresentar problemas com relação } \\
\text { à qualidade dos produtos fabricados. }\end{array}$ \\
\hline $\begin{array}{l}\text { Layout Funcional } \\
\text { ou Por Processo }\end{array}$ & $\begin{array}{l}\text { Flexível para atender a mudanças de mercado; Atende a produtos } \\
\text { diversificados em quantidades variáveis ao longo do tempo; }\end{array}$ \\
\hline & $\begin{array}{l}\text { Apresenta um fluxo longo dentro da fábrica; } \\
\text { Adequado a produção diversificadas em pequenas e médias } \\
\text { quantidades; Possibilita uma relativa satisfação no trabalho. }\end{array}$ \\
\hline Layout por & Especificações do produto; Características do produto: dimensões \\
\hline Posição Fixa & $\begin{array}{l}\text { especiais; Quantidade de produto e de materiais; Sequências de } \\
\text { operações e de montagem; Espaço necessário para cada } \\
\text { equipamento: incluindo espaço para movimentação do operador. }\end{array}$ \\
\hline
\end{tabular}

Fonte: Adaptado de MARTINS e LAUGENI, 2012; SLACK et al, 2008; NEUMANN, 2015; FEUP, 2015.

A decisão de qual arranjo físico escolher envolve uma escolha entre os quatro tipos básicos. As características de volume e variedade de uma operação vão reduzir a escolha, a uma ou duas opções (NEUMANN, 2015). Na figura 1, é possível compreender o desempenho de cada layout: 
Figura 1 - Tipos de layout: variedade versus volume

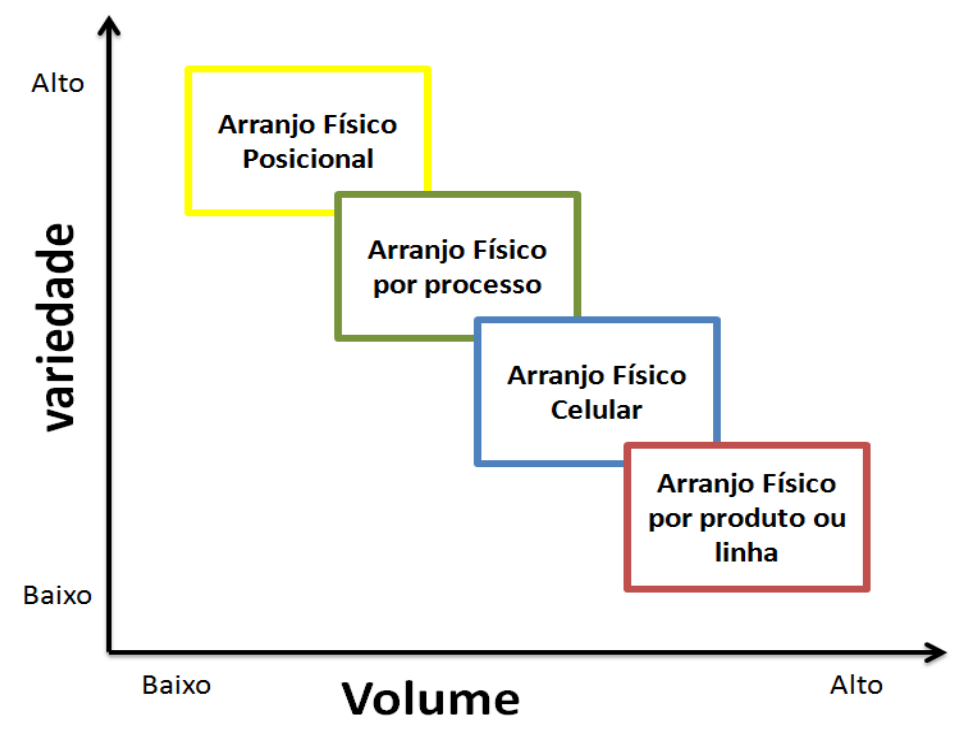

Fonte: Adaptado de SILVEIRA (1998)

Cada tipo pode estar sujeito a variações de variedade e volume, neste caso, saber qual tipo escolher é de fundamental importância para uma excelente aplicação.

Para se produzir grandes quantidades com baixa variedade é interessante optar pela escolha do Layout por Produto ou Linear e pelo Layout Celular, pois ambos têm características de alta performance em relação a produção de altos volumes. Se optar por uma variedade grande de produtos de baixo volume é indicado escolher o arranjo físico posicional ou por processo, já que, ambos possuem muita flexibilidade e adaptação para produtos diferentes.

Uma boa decisão sobre qual tipo de layout escolher pode ser um fator determinante para uma boa gestão da fábrica, visto que uma mudança de layout pode gerar custos e perdas consideráveis de produção.

A implantação do layout tem dificuldades em relação ao elevado custo e também a sua longa duração, como por exemplo, em processos complexos que necessitam da mudança de local dos equipamentos a duração pode ser longa (FERREIRA e REAS, 2013).

Quando erros são causados no processo de mudança ou no projeto do layout, falhas podem ocorrer, prejudicando o consumidor interno e externo e consequentemente ocasionando confusões nos estoques (KANNAN, 2010; SINGH; YILMA, 2013).

O OEE é uma ferramenta simples que ajuda a gestão a ter uma visão da produtividade em relação à qualidade e a eficiência da planta de fabricação. Através desses cálculos é possível detectar onde estão as falhas no processo e assim planejar e propor melhorias (SINGH, 2013). 
Ele é utilizado como uma ferramenta que mede o desempenho do sistema produtivo de forma simples, considerando as perdas de produtividade e as agregando em disponibilidade, desempenho e qualidade. Sendo elas consideradas indicadores de eficiência do equipamento. Estas, categorias, proporcionam uma análise da situação dos processos, mostrando ineficiências ocultas nas operações de manufatura (SINGH, 2013).

Conforme a figura 2, os três indicadores que são adotados para analisar as perdas são:

Figura 2 - Indicadores de perdas OEE

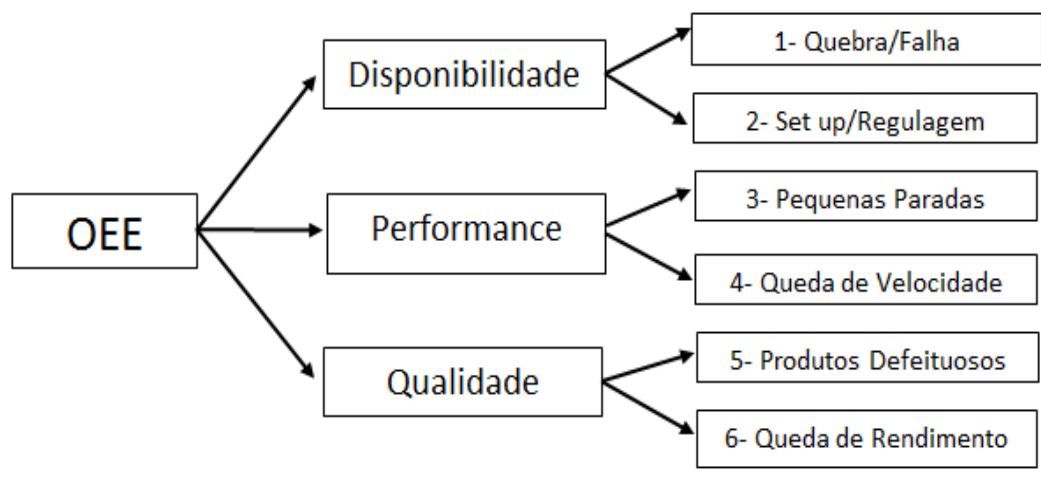

Fonte: Adaptado de SINGH (2013)

O OEE, também é considerado como o indicador principal para quantificar a eficiência global de uma operação ou processo, muito utilizado por industrias e empresas dos mais diversos segmentos. Ele pode estar inserido dentro de um software de computador como por exemplo os programas associados ao TPM (Total Productive Maintenance), dando suporte a responder questões do tipo: frequência da disponibilidade dos equipamentos para trabalhar, rapidez no processo de produção, quantidade de produtos produzidos sem apresentar defeito, dentre as demais relacionadas (MORALES et al, 2015).

Com as respostas obtidas estruturadas nos conceitos do OEE e TPM, é possível interpretar grande parte do sucesso e do fracasso de qualquer processo produtivo, por estes motivos são técnicas e indicadores tão respeitados por indústrias e empresas (FOURIE, 2016).

Voltando a tratar especificamente sobre o $O E E$, pesquisas apontam que o ganho de $1 \%$ na estrutura do $O E E$, equivale de 3 à 7 no faturamento da operação ou processo analisado. A integração de áreas também pode ser alcançada com análises realizadas quando as mesmas forem elaboradas com base na estrutura do $O E E$, já que todos os processos e operações serão afetados com as mudanças propostas pelo $O E E$, favorecendo a empresa na identificação de diversos pontos que contribuem para a evolução e melhor desempenho da organização (FOURIE, 2016).

Os resultados de melhoria da indústria ou empresa podem estar ligados a fatores como: definir qual a pior ou melhor máquina dentro do processo ou operação, há 
necessidade de manutenção nas máquinas, o estado das máquinas é satisfatório ou já atingiram o fim de seu ciclo de vida, existe a necessidade e ampliação da planta fabril, projetar novas linhas de produção, aumentar a quantidade colaboradores, autorizar horas extras, ou até mesmo dividir a jornada de trabalho em turnos (GOYAL et al., 2013).

\section{ESTUDO DE CASO}

A empresa estudada pertence ao ramo automotivo e está localizada no interior do Estado de São Paulo. Com uma vasta experiência de mercado automobilístico, ela conta com um portfólio amplo, produzindo dispositivos de segurança, sistemas de freios e desenvolvendo tecnologia de segurança.

Recentemente a empresa readequou sua área para comportar um novo setor de linhas de estamparia, aumentando sua produção para suprir a atual demanda.

No período de pesquisa, em maio de 2016, a fábrica acomodava no setor de usinagem em torno de 15 células, dispostas em montagem, estamparia e usinagem, no qual a célula a ser pesquisada foi uma das células de usinagem de discos de freio para o mercado nacional e reposição.

Figura 3 - Arranjo físico da célula de usinagem de disco antes da mudança

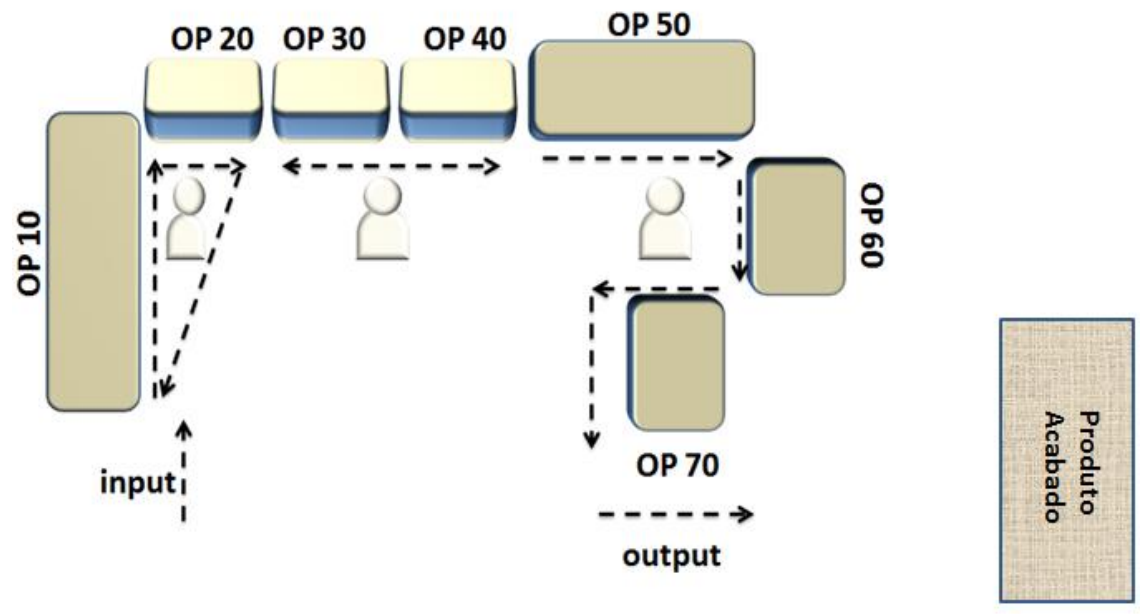

Fonte: Autoria Própria (2019)

O motivo do estudo desta célula, se deu pela necessidade de mudança de layout para acomodar outras células de usinagem no setor e também pelo alto nível de pedidos, que ocorreram nesta época do ano decorrentes de novos acordos comerciais.

Com a chegada desse novo montante fabril, houve-se a necessidade de reajustar esta célula de usinagem. Foi então, inserida uma nova linha de usinagem bem próximo à saída de produto acabado, ocasionando assim uma alteração forçada de layout. Como pode-se observar na figura 4. 
Figura 4 - Arranjo físico da célula de usinagem de disco depois da mudança

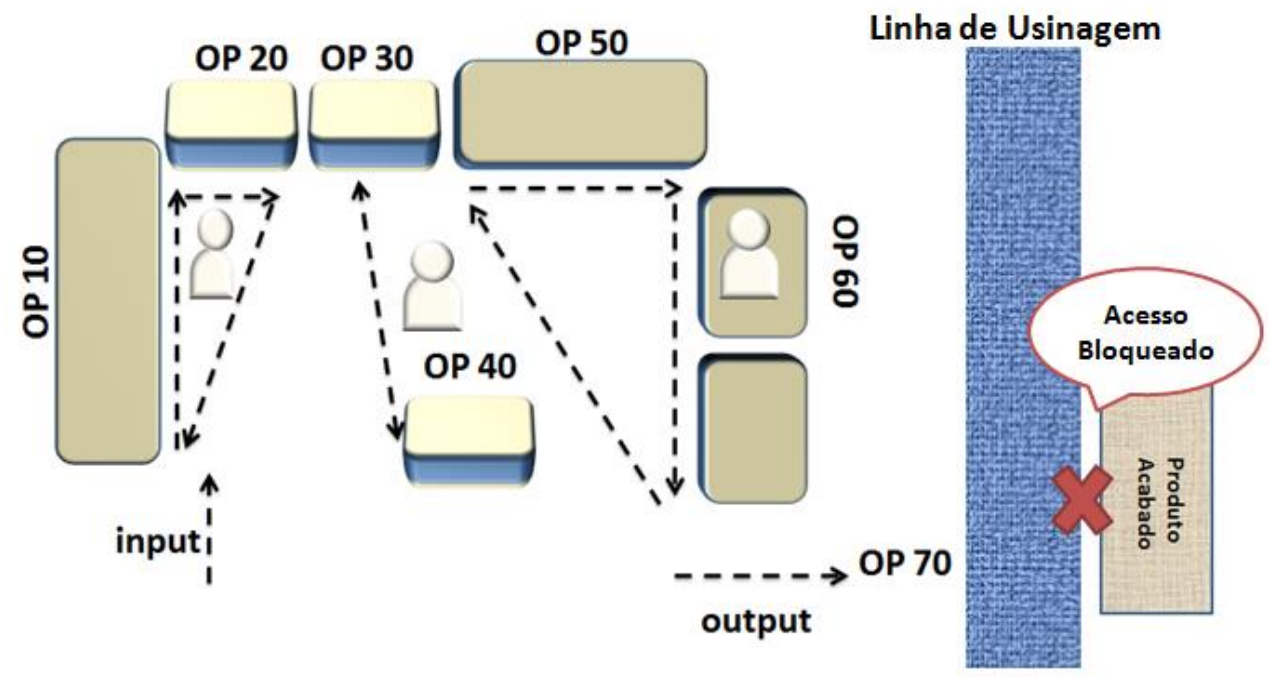

Fonte: Autoria própria (2018)

As alterações, diminuíram o espaço da célula, e a principal mudança foi a realocação da operação 40 e 70, mudou-se também o output da célula, ocasionando uma movimentação maior do produto acabado até o ponto de recolhimento. Um comparativo foi feito entre os dados de antes e o depois da mudança de layout, e evidenciou o prejuízo causado, ilustrado no Gráfico 1.

Gráfico 1 - Gráfico de acompanhamento de OEE da célula

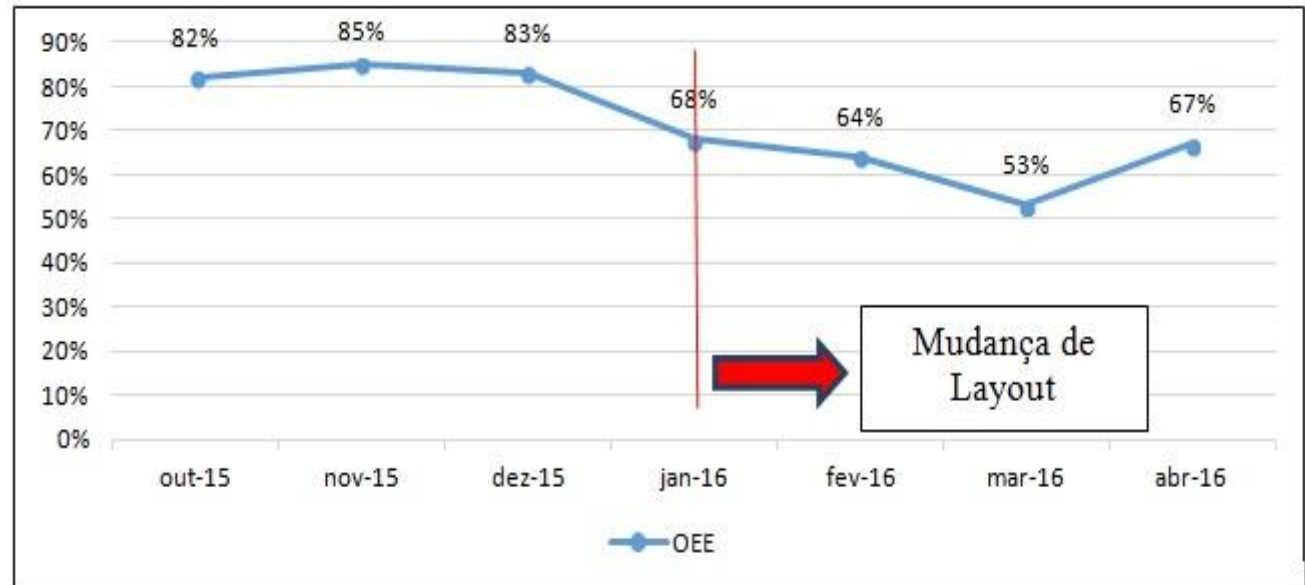

Fonte: Autoria própria (2018)

Analisando o Gráfico 1, percebe-se que o indicador de $O E E$ da célula teve uma baixa considerável após a mudança iniciada em janeiro.

Sendo o OEE uma equação entre, Performance, Disponibilidade e Qualidade, o principal item que fez com que ocorresse a queda de rendimento no indicador foi a Performance, uma vez que, um dos subitens que são as paradas não 
programadas, elevaram-se após a mudança. Isto ocorreu devido a saída do produto da célula, onde ficou exposta uma movimentação desnecessária por parte do operador, causada pela obstrução das saídas da linha.

Outro indicador observado foi o Diagrama de Pareto, nele foi possível observar as porcentagens que foram determinantes para o estudo, indicados no Gráfico 2.

Gráfico 2 - Diagrama de Pareto com os principais motivos de perdas existentes na célula

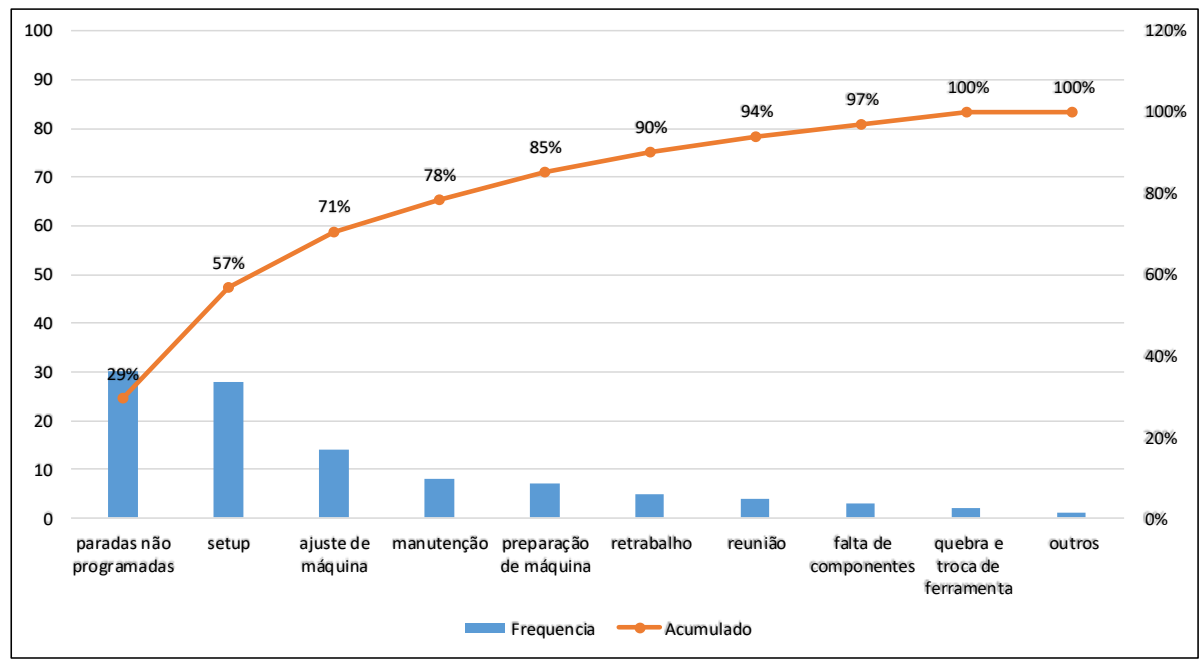

Fonte: Autoria própria (2018)

Antes de propor qualquer mudança, foram medidos os tempos de ciclo atual do produto e a capacidade produtiva, levando em consideração que a célula trabalha com 3 operadores, onde existe a presença de um gargalo na operação 10.0 tempo total entre ciclo de máquina e movimentação do operador é de 225 segundos, como pode ser analisado no Gráfico 3.

Gráfico 3 - Tempo de ciclo de cada operação em segundos

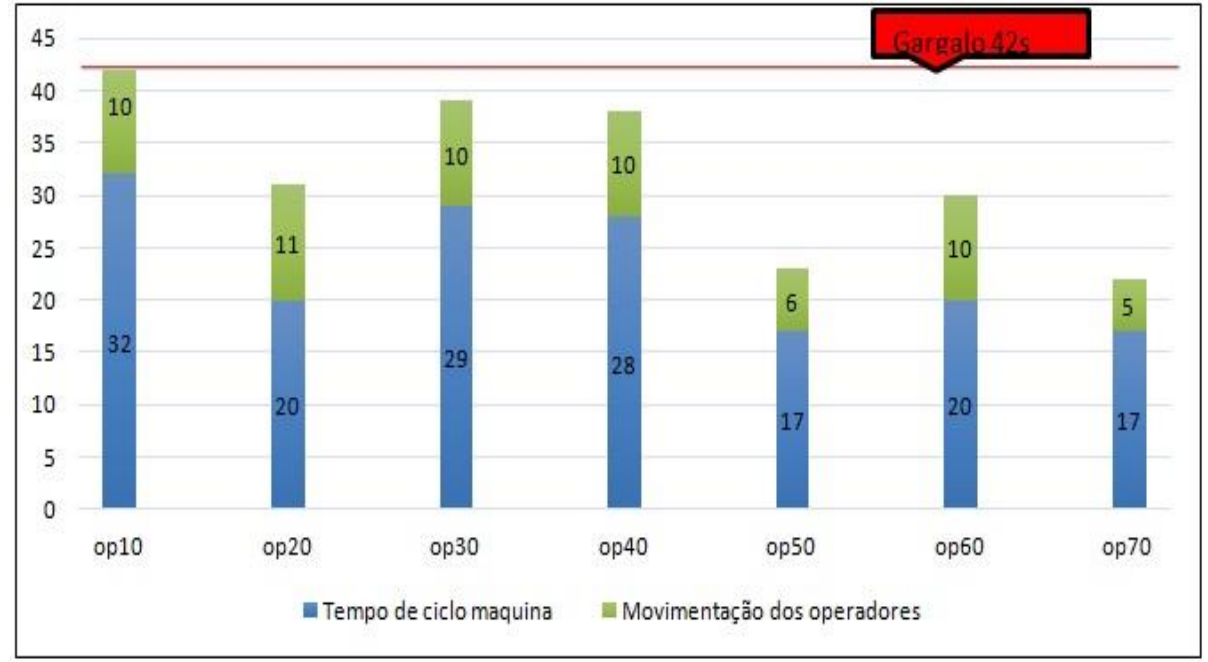

Fonte: Autoria própria (2018) 


\section{PROPOSTA DE ALTERAÇÃO DE LAYOUT}

Com os dados levantados durante o estudo, foi proposta uma mudança que proporcionasse pouco impacto no layout, que economizasse os custos de movimentação das máquinas e que não tivesse efeito no layout atual, em que se encontrava a célula.

Desenvolveu-se então um novo arranjo físico, utilizando um layout celular em $U$, onde foi priorizado o fluxo contínuo do produto, e uma menor movimentação dos operadores.

Para a formulação do novo layout foi adotado novamente os cálculos de tempos e movimentos, porém desta vez aplicou-se este estudo visando um sistema mais enxuto e uma melhor distribuição das máquinas e equipamentos na célula com avaliação e aprovação dos operadores. Aproveitou-se também o conceito de Lean Manufacturing, para eliminação dos possíveis desperdícios, além de priorizar o fluxo de entrada e saída de materiais da célula melhorando a logística interna. Com estes conceitos foi elaborado o novo arranjo físico, conforme a Figura 5:

A principal mudança efetuada foi a realocação da OP10, e o realinhamento da OP60 e OP70, elas abriram espaço interno transformando a linha em uma célula em " $U$ ". As demais operações foram apenas realocadas sem a necessidade de uma mudança mais acentuada e os operadores também não sofreram nenhuma mudança.

Figura 5 - Layout proposto

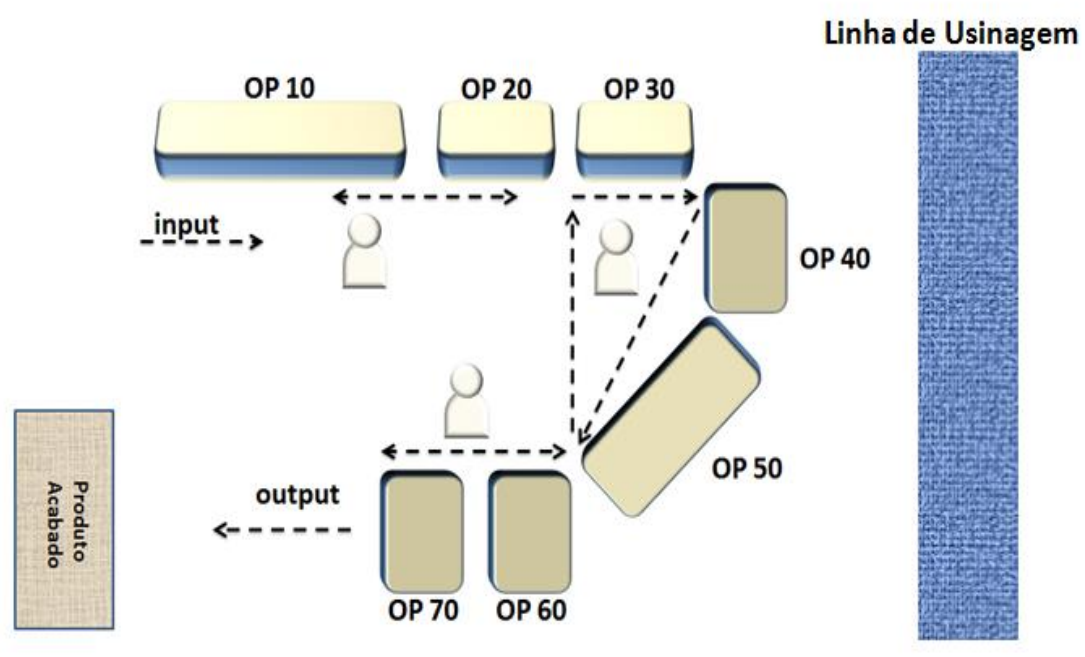

Fonte: Autoria própria (2018)

\section{AVALIAÇÃO DOS RESULTADOS}

Percebe-se que, o ponto forte desse novo arranjo físico é a facilidade com que o produto entra e sai sem a necessidade de o operador parar o posto de trabalho, isso facilita a retirada do produto pela empilhadeira otimizando a logística interna. Outro ponto que pode ser destacado é a diminuição de movimentação do 
operador que trabalha no gargalo, ele ganha assim, uma melhora na sua eficiência. Uma prévia no estudo garantiu ganhos de no mínimo 6 segundos nas operações em que ele efetuava, abaixando o tempo total de ciclo da célula em torno de $3 \%$, como pode-se observar no Gráfico 4.

Gráfico 4 - Tempos de ciclo após mudança de Layout em segundos

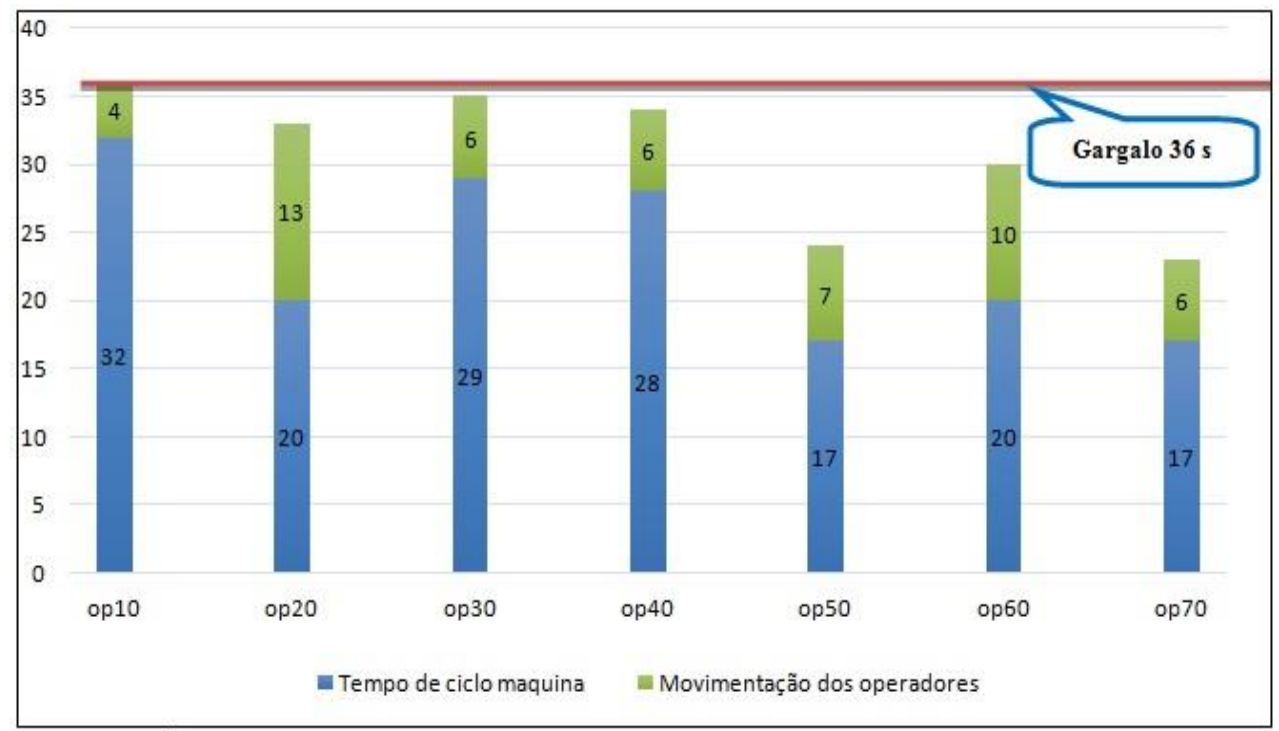

Fonte: Autoria própria (2018)

Também com a melhora do fluxo de saída de produto acabado da célula, o operador do final de linha não precisará mais parar sua operação, extinguindo parcialmente um dos principais itens em destaque do Diagrama de Pareto, ilustrado no Gráfico 5, que são as paradas não programadas.

Gráfico 5 - Diagrama de Paretos com as principais perdas depois da mudança de layout

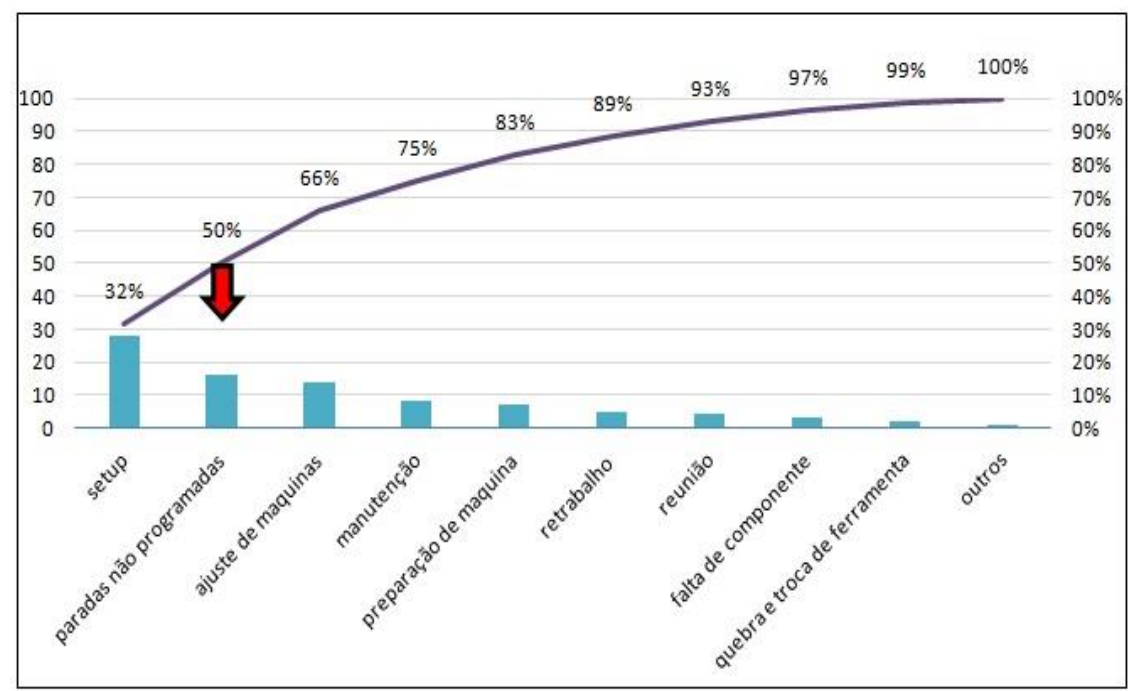

Fonte: Autoria própria (2018) 
Com novos valores de performance obtido pela alteração de layout foi possível estabelecer novos índices de $O E E$ como pode ser visto no Gráfico 6.

Gráfico 6 - Índices de OEE de acordo com as mudanças de layout

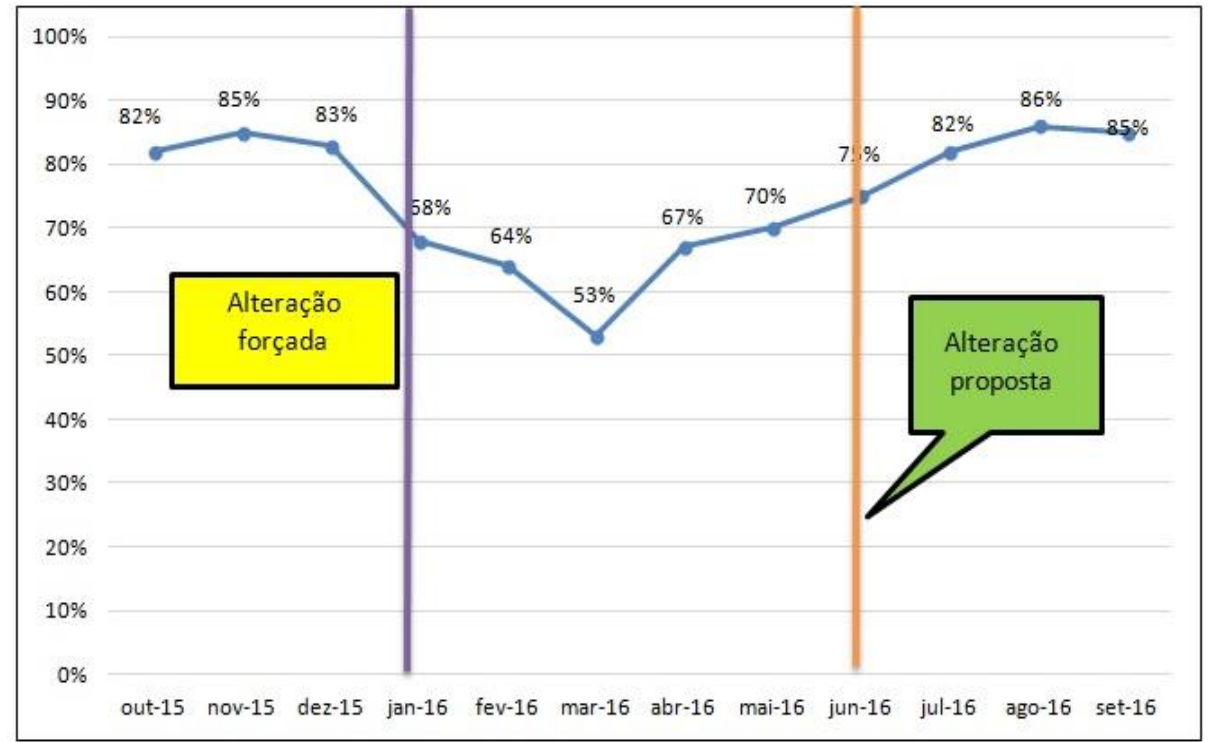

Fonte: Autoria própria (2018)

\section{CONCLUSÕES}

O propósito desta pesquisa foi analisar e propor propostas para melhoria de um layout numa linha de produção que sofreu um realinhamento devido a mudança de mercado da organização. A proposta necessitava ser de pouco impacto na alteração e visionava a redução de movimentação dos operados entre as máquinas das linhas.

Assim sabendo que um layout mal organizado pode propiciar baixa produtividade e uma qualidade ruim, a reorganização do layout do caso estudado evidenciou melhorias nos índices de $O E E$ da linha de produção. Por conseguinte, em resposta ao problema de pesquisa deste artigo, as propostas que precisavam ser feitas para melhorar o arranjo físico desta linha de produção foram a realocação da OP10 e, o realinhamento da OP60 e OP70, que permitiram um espaço interno maior na linha de produção e seu alinhamento de célula em "U". Desta maneira, o espaço de produto acabado desta linha foi realocado para o lado oposto ao que estava.

Com o objetivo de propor uma mudança de layout de acordo com o estudo dos tempos dos equipamentos, da movimentação dos operadores e também do tempo de fluxo do produto, levando em consideração todo o espaço físico atual, esta mudança proporcionou a cada operador desta linha de produção ganhos de no mínimo 6 segundos em suas operações, reduzindo o tempo total de ciclo desta linha em aproximadamente $3 \%$, já que esse novo layout facilitou a entrada e saída do produto e permitiu que o produto seja retirado por empilhadeira, reduzindo assim os esforços dos operadores e otimizando a circulação interna. 
Pode-se concluir, que apesar da proposta para este trabalho foi melhorar o fluxo do processo, também ocorreram ganhos referentes à movimentação, paradas desnecessárias e a ergonomia, sem contar que o principal objetivo foi alcançado, a melhora do fluxo resultou em altos índices de produtividade em um espaço reduzido atendendo a necessidade da empresa.

A atuação do engenheiro de produção no setor produtivo tem grande importância, pois somente com a base em estudos e conhecimento pode-se obter bons projetos como o que foi apresentado neste artigo, servindo de referência para próximos trabalhos e projetos de layout, readequação do espaço fabril e pesquisas referentes a qual layout utilizar.

Como finalização deste trabalho, considera-se pertinente apresentar as limitações do mesmo. Essa pesquisa foi realizada em único caso, apresentando dados limitados a um determinado ambiente. Todavia, sugere-se que trabalhos futuros sejam realizados baseados nas premissas aplicadas por esses autores em diferentes segmentos. Também se consideram limitações às análises de propostas não serem feitas por meio de softwares de simulação, o que proporcionaria elucidar melhor as dimensões e encontrar novas possibilidades. Porém, apesar de poucos recursos, os resultados foram satisfatórios e indiscutíveis. 


\title{
Proposal to change layout for improvement in the production flow of an Automotive Industry
}

\begin{abstract}
:
The research problem of this work is delimited in the verification of possible improvement in a physical arrangement of a certain one in the production line. With the objective of presenting alternatives to solve the deficiencies found in the changes of the layout of the factory from a case study, applying a layout change according to the study of the time of the equipment, the movement of the operators and also the time of The methodology employed in this practical study was structured to search in the scientific literature focused on Production Engineering, the concepts of OEE (Overall Equipment Effectiveness) and TPM (Total Productive Maintenance) and As a result, the layout change provided each operator of this production line gains of at least 6 seconds in their operations, reducing the total cycle time of this line by approximately $3 \%$, already that this new layout facilitated the entry and exit of the product and allowed the product to be removed by forklift, reduces thus enhancing the operators' efforts and optimizing internal circulation.
\end{abstract}

KEY-WORDS: Layout, Automotive, Physical Arrangement. 


\section{REFERÊNCIAS}

ALLAIS, R.; REYES, T.; ROUCOULES, L. Inclusion of territorial resources in the product development process. Journal of Cleaner Production, v. 94, p. 187-197, 2015. crossref

Azevedo, M. M.; CRISPIM, J. A.; de SOUSA, J. P. A dynamic multi-objective approach for the reconfigurable multi-facility layout problem. Journal of Manufacturing Systems. v. p. 42, 140-152, 2017.

CHIARADIA, A. J. P. Utilização do indicador da eficiência global de equipamentos na gestão e melhoria contínua dos equipamentos: um estudo de caso na indústria automobilística. Dissertação (Mestrado Profissionalizante em Engenharia). Porto Alegre, 2004.

D'ANTONIO, G. et al. An integrated mathematical model for the optimization of hybrid product-process layouts. Journal of Manufacturing Systems, v. 46, p. 179192, 2018. crossref

ESMAEEL, R. I., ZAKUAN, N., JAMAL, N. M., TAHERDOOST, H. Understanding of business performance from the perspective of manufacturing strategies: fit manufacturing and overall equipment effectiveness. Procedia Manufacturing, 22, 998-1006, 2018. crossref

FAHAD, M. et al. Energy Management in a Manufacturing Industry through Layout Design. Procedia Manufacturing,v. 8, p. 168-174, 2017.

FERNANDES, G.; STRAPAZZON, R.; CARVALHO, A. P. Layout de Empresas e seus Benefícios. 2016.

FERRÀS-HERNÁNDEZ, X.; TARRATS-PONS, E.; ARIMANY-SERRAT, N. Disruption in the automotive industry: A Cambrian moment. Business Horizons, v. 60, n. 6, p. 855-863, 2017. crossref

FERREIRA, J.C.E; REAES, P.A. Performance comparison of the virtual cell layout with cellular and job shop configurations using simulation and design of experiments. In: 9th IEEE International Conference on Automation Science and Engineering. IEE CASE, Madison, Wisconsin, EUA: IEEE Robotics and Automation Society, 2013. crossref

FOURIE, H. Improvement in the overall efficiency of mining equipment: A case study. Journal of the Southern African Institute of Mining and Metallurgy, v. 116, n. 3, p. 275-281, 2016. crossref 
GOYAL, K. K.; JAIN, P. K.; JAIN, M. A novel methodology to measure the responsiveness of RMTs in reconfigurable manufacturing system. Journal of Manufacturing Systems, v. 32, n.4, p. 724-730, 2013. crossref

HALLSTEDT, S. I.; THOMPSON, A. W.; LINDAHL, P. Key elements for implementing a strategic sustainability perspective in the product innovation process. Journal of Cleaner Production, v. 51, p. 277-288, 2013. crossref

JONES, Gareth R.; GEORGE, Jennifer M. Administração Contemporânea. 4a edição. São Paulo: McGraw-Hill, 2008.

KANNAN, V. R; TAN, K. C. Supplier Selection and Assessment: Their Impact on Business Performance. Journal of Supply Chain Management, 2010.

KIRAN, D. R. Total quality management: Key concepts and case studies. Butterworth-Heinemann, 2017.

MARTINS, Petrônio Garjia; LAUGENI, Fernando Piero. Administração da Produção. 2. ed. São Paulo: Saraiva, 2012.

MARZAGÃO, D. S. L.; CARVALHO, M. M. Critical success factors for Six Sigma projects. International Journal of Project Management, v. 34, n. 8, p. 1505-1518, 2016. crossref

MORALES VARELA, A. et al. Modelo de un sistema de producción esbelto con redes de Petri para apoyar la toma de decisiones Ingeniare. Revista Chilena de Ingeniería, v. 23, n. 2, p. 182-195, 2015.

NEUMANN, C.; Scalice, R. Projeto de fábrica e layout. Vol. 1. Elsevier Brasil, 2015.

NEUMANN, C. S. R.; FOGLIATTO, F. S. A method to measure and improve layout flexibility in dynamic environments. Gestão \& Produção, v. 20, n. 2, p. 235-254, 2013.

NEVES, P. C.; AFONSO, Ó.; SEQUEIRA, T. Population growth and the wage skill premium. Economic Modelling, v. 68, p. 435-449, 2018. crossref

OLIVEIRA, M. R.; HEMOSILLA, J. L. G.; SILVA, E. C. C. Implantação do Índice de Eficiência Global dos Equipamentos em uma Célula de Manufatura de uma Empresa de Grande Porte do Setor Automotivo - Segmento de Embreagens. Anais do XV Simpósio de Administração da Produção, Logística e Operações Internacionais - SIMPOI. São Paulo, 2012. 
RAHMAN, S. M. T.; SALIM, M. T.; SYEDA, S R. Facility layout optimization of an ammonia plant based on risk and economic analysis. Procedia Engineering, v. 90, p. 760-765, 2014. crossref

ROSA, G. P. et al. A reorganização do layout como estratégia de otimização da produção. Gepros: Gestão da Produção, Operações e Sistemas, v. 9, n. 2, p. 139, 2014.

SUJOVA, Andrea. Influence of the Economic Crisis in 2008 on the Performance of Companies in Wood-processing Industry. Procedia Economics and Finance, v. 34, p. 581-586, 2015. crossref

Tipos de Processos da Produção na Industria e nos Serviços. Faculdade de Engenharia da Universidade do Porto. Disponivel em:

<https://paginas.fe.up.pt/ ee95078/trab/eg/indice.html>. Acesso em: 08 de Fevereiro de 2019.

SILVEIRA, G. J. C. Das prioridades estratégicas ao gerenciamento de trade-offs: três décadas de estratégia de produção. Revista de Administração. São Paulo, v.33, n. 3, julho/setembro 1998.

SINGH, A. P.; YILMA, M. Production floor layout using systematic layout planning in Can manufacturing company. In: IEEE International Conference on Control, Decision and Information Technologies. CoDIT, Hammamet, Tunisia, 2013. crossref

SINGH, R., SHAH, D. B., GOHIL, A. M.; SHAH, M. H. Overall Equipment Effectiveness (OEE) calculation-Automation through hardware \& software development. Procedia Engineering, v.51, p. 579-584, 2013. crossref

SLACK, N.; CHAMBERS, R.; JOHNSTON, R. Administração da Produção. 2.ed. São Paulo: Atlas. 2008.

ZERELLA, S., VON TREUER, K.; ALBRECHT, S. L. The influence of office layout features on employee perception of organizational culture. Journal of Environmental Psychology, v.54, P.1-10, 2017. crossref 
Recebido: 11 jul. 2018

Aprovado: 25 fev. 2019

DOI: $10.3895 /$ gi.v15n1.8546

Como citar:

GENNARO, C. K.; OLIVEIRA, E. D.; OLIVEIRA, F. F.; SILVA, D. F. Proposta de alteração de layout para melhoria no fluxo de produção de uma Indústria Automotiva. R. Gest. Industr., Ponta Grossa, v. 15, n. 1, p. 212-230, jan./mar. 2019. Disponível em: <https://periodicos.utfpr.edu.br/rgi>. Acesso em: XXX.

Correspondência:

Carline Kühl Gennaro

Rua Santa Inês, 185, Apto 64 Luna, Vila Belvedere, Americana, São Paulo, Brasil

Direito autoral: Este artigo está licenciado sob os termos da Licença Creative Commons-Atribuição 4.0 Internacional.

\section{(c) (1)}

